\title{
PEMBERDAYAAN ISTRI NELAYAN MELALUI PELATIHAN DIGITAL MARKETING STRATEGY (DMS) DARAH BIRU
}

\author{
Nisaul Azizah*1, Erly Rofianti Wahyudi², Khoirrun Nissa ${ }^{3}$, \\ Amelia Fibrianti Wahyudi ${ }^{4}$, Siti Khoiruli Ummah ${ }^{5}$ \\ ${ }^{1}$ Program Studi Pendidikan Matematika, Fakultas Keguruan dan Ilmu Pendidikan, Universitas \\ Muhammadiyah Malang \\ ${ }^{2}$ Program Studi Pendidikan Biologi, Fakultas Keguruan dan Ilmu Pendidikan, Universitas \\ Muhammadiyah Malang \\ ${ }^{3}$ Program Studi Manajemen, Fakultas Ekonomi dan Bisnis, Universitas Muhammadiyah Malang \\ Universitas Muhammadiyah Malang; Jalan Raya Tlogomas 246 Malang, 0341460435 \\ *E-mail: nisaulazizah1997@gmail.com
}

\begin{abstract}
The fisherman's wife was one of the nonproductive community that couldn't get salary by themselves. The horseshoe crab was the most crab that live in Mayangan's village. Usually, the community eat this crab and throw the blood away. In fact, this blood, blue colored, has many advantages in pharmacy area that one of ingredient to produce the medicines. The training was needed by community to produce and market the blue blood using digital marketing strategy. The training method covers the formation of caders, the packaging product, creating e-commerce account, the marketing strategy, finacial bookkeeping, and evaluating the use of digital marketing strategy. The training objects were five fisherman's wives who live in Mayangan Villege and couldn't earn the salary. After the training held, the community has computer skill and ecommerce account to promote the blood. They also could package the blood that must have good quality in several days. They also were skilled in financial bookkeeping and manage the ecommerce account. Finally, this community could earn the salary by themselves using the production and digital marketing strategy.
\end{abstract}

Keywords — training, digital marketing strategy, blue blood

\begin{abstract}
Abstrak
Istri nelayan merupakan salah satu masyarakat nonproduktif ditinjau dari kemandirian dalam mendapatkan penghasilan. Darah biru merupakan salah satu komponen pada kepiting tapal kuda yang sangat melimpah di Desa Mayangan. Biasanya, kepiting diolah sebagai masakan dengan proses pembuangan darah biru. Darah biru merupakan salah satu bahan baku obat sehingga diperlukan di bidang farmasi. Pemanfaatan darah biru ini perlu diberikan kepada mitra dan dipasarkan sehingga dapat memberikan penghasilan bagi istri nelayan. Kegiatan pelatihan ini bertujuan untuk memberdayakan istri nelayan agar menjadi masyarakat mandiri dengan memproduksi ekstrak darah biru dan memasarkannya melalui sarana digital. Metode pelaksanaan pelatihan diawali dari sosialisasi, pembentukan kader, strategi pengemasan produk, pembuatan akun e-commerce, strategi pemasaran, strategi pembukuan keuangan, dan evaluasi pemasaran digital. Sasaran pelatihan yaitu lima orang istri nelayan di Desa Mayangan yang tidak mempunyai pekerjaan. Hasil kegiatan ini yaitu adanya kemandirian masyarakat yang ditinjau dari adanya penghasilan yang diperoleh melalui strategi pemasaran darah biru. Penggunaan e-commerce sebagai sarana pemasaran digital dikelola dengan baik sehingga mampu menambah skill mitra di bidang komputasi. Mitra telah mempunyai pembukuan keuangan. Pengkaderan yang dilakukan bertujuan untuk keberlangsungan produksi dan pemasaran darah biru.
\end{abstract}

Kata kunci-pelatihan, digital marketing strategy, darah biru 


\section{PENDAHULUAN}

Masyarakat Desa Mayangan, Kota Probolinggo sebagian besar bermata pencaharian nelayan dengan persentasi istri nelayan adalah $75 \%$. Istri nelayan kebanyakan menjadi ibu rumah tangga, sebagai ibu rumah tangga kebutuhan hidup masih bergantung pada seorang suami dalam kehidupan sehari-harinya. Pendidikan terakhir istri nelayan yang berada di Mayangan, Kota Probolinggo yakni kebanyakan lulusan Sekolah Menengah Pertama. Rata-rata umur istri nelayan yakni antara 25-50 tahun. Masyarakat di Desa Mayangan, Kota Probolinggo sebagian besar memiliki mata pencaharian sebagai nelayan. Namun, dari hasil bernelayan tersebut belum mampu meningkatkan penghasilan keluarga. Sistem pembagian kerja masyarakat pesisir dan tidak adanya kepastian penghasilan setiap hari dalam rumah tangga nelayan telah menempatkan perempuan sebagai salah satu pilar penyangga kebutuhan hidup rumah tangga [1]. Setengah dari total kebutuhan rumah tangga, ditanggung oleh perempuan atau istri. Sehingga istri nelayan memiliki peran mencari nafkah untuk mengatasi dan menyangga kebutuhan rumah tangga [2].

Fasilitas perdagangan dan jasa di desa Mayangan terdiri dari 6 pasar umum, 153 toko swalayan yang tersebar di beberapa tempat, 3 rumah makan, 260 warung/kios dan 70 bangunan jasa. Sistem transportasi jalan raya secara umum perangkutan yang berkembang di desa Mayangan adalah perangkutan darat dan laut. Kegiatan perangkutan lebih didominasi oleh kegiatan perangkutan darat pada jalan raya dengan menggunakan jenis alat transportasi terdiri dari kendaraan roda empat, dan roda dua. Sistem transportasi laut yang berada di daerah pesisir pantai memiliki prasarana transportasi laut berupa Pelabuhan yang terletak pada Kecamatan Mayangan. Prospek jalan di Desa Mayangan baik pada tansportasi darat yang dapat digunakan untuk kendaraan roda empat, dan kendaraan roda dua. Dengan adanya lintas jalur utama ke Probolinggo dapat memudahkan konsumen untuk pembelian kepiting tapal kuda di Desa Mayangan.

Desa Mayangan memiliki bahasa sehari-hari yang beragam tetapi masyarakat lokal menggunakan Bahasa Jawa dan Madura yang terkenal ulet, lugas, terbuka dan kuat dalam mengarungi kehidupan (berjiwa wiraswasta tinggi). Selain itu perpaduan dan budaya yang masih asli dicerminkan dengan gotong royong, dan adat budaya khas, serta diwarnai dengan unsur Islam. Sebagian besar penduduk desa Mayangan bermata pencaharian sebagai nelayan. Istri nelayan tidak bekerja namun penghasilan keluarganya rendah.

Aspek perekonomian yang ada di desa Mayangan meliputi komoditi pertanian, perkebunan, perikanan, tambak, peternakan, dan industri. Sektor perikanan merupakan sektor yang dominan di desa Mayangan terutama dikawasan pesisir dan laut. Potensi perikanan yang utama didominasi oleh perikanan laut dan tambak yang berada di sebelah utara Kecamatan Mayangan dan berkembang disepanjang pantai. Penghidupan warga Desa Mayangan, umumnya adalah nelayan. Di sekitaran pesisir tanjung tembaga banyak terdapat kepiting tapal kuda. Namun sangat disayangkan, masyarakat disana tidak mengetahui khasiat dari racun biru pada kepiting tapal kuda. Racun biru pada kepiting tapal kuda sangat membantu prospek usaha di desa Mayangan Kota Probolinggo.

Desa Mayangan merupakan salah satu daerah pesisir dengan salah satu hasil tangkapannya berupa kepiting tapal kuda. Kepiting tapal kuda biasa disebut Belangkas, Kepiting ladam, Mimi, Kepiting Tapal Kuda, Mintuna, Kepiting Bulan (Tachypleus gigas) [3]. Kepiting ini merupakan salah satu sumberdaya genetika yang dilindungi sesuai dengan SK Menteri Kehutanan No. 12/Kpts-II/1987 dan Peraturan Pemerintah RI No. 7/1999 [4]. Salah satu keunikan yang dimiliki kepiting ini yaitu darah yang berada di dalam tubuh tidak mengandung Hemoglobin melainkan mengandung Hemocyanin. Kandungan ini berfungsi untuk mengangkut oksigen dan mengandung unsur tembaga yang mengakibatkan warna darah kepiting menjadi biru [5]. Darah kepiting juga mengandung unsur amebosit yang berfungsi sebagai pertahanan organisme untuk melawan patogen. Amebosit ini yang akan membuat Limulusamebocyte lysate (LAL) sebagai alat pendeteksi kandungan endotoksin bakteri dalam pengobatan. LAL mempunyai banyak manfaat terutama di bidang medis. Salah satu manfaat LAL yaitu sebagai detector alat medis sehingga bebas dari kandungan bakteri dan jamur [6]. Manfaat lain dari LAL ini yaitu sebagai bahan baku pembuatan vaksin [7]. Kepiting Tapal Kuda dapat dilihat pada Gambar berikut: 


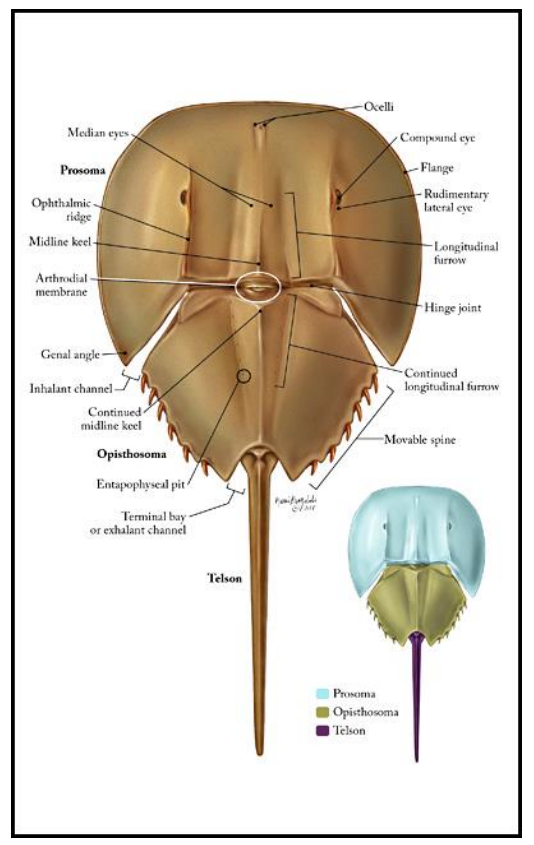

Gambar 1 Bentuk Kepiting Tapal Kuda (Horseshoe Crab)

Adopsi dari Jurnal Bergdale [8]

Pemanfaatan LAL tes untuk menguji kandungan bakteri dan jamur pada alat kesehatan dilakukan dengan cara mengambil darah biru pada kepiting. Sel darah disentrifugasi dan proses lisis pada air suling untuk melepaskan cascade enzim yang berfungsi untuk mengenali endotoksin. Pengujian sampel untuk endotoksin dilakukan dengan mencampur sampel dengan lysate pada rasio yang ditetapkan [9]. Biasanya, produk berupa gel beku. Pentingnya darah biru dari kepiting tapal kuda di bidang biomedis maupun biokimia memungkinkan darah biru ini bernilai jual tinggi. Ecommerce Alibaba menyebutkan terdapat darah biru yang dijual dalam satuan liter dengan harga \$2500-3000.

Kepiting tapal kuda dapat diperoleh lebih banyak jika musimnya, jika tidak musim kepiting tapal kuda. Selama ini kepiting tapal kuda digunakan sebagai makanan lauk pauk pada bagian daging dan telurnya. Untuk bagian cangkang dari kepiting tapal kuda banyak digunakan sebagai kerajinan atau hiasan yang memiliki nilai jual. Daging dan telur dari kepiting tapal kuda ini banyak dikonsumsi oleh masyarakat dan banyak ditemukan di pasar ikan yang tidak jauh dari laut. Penjual kepiting tapal kuda umumnya adalah warga sekitar laut yang berprofesi sebagai istri nelayan. Jarang sekali nelayan memanfaatkan darah biru pada kepiting tapal kuda. Umumnya, ketika kepiting dikonsumsi, darah biru dibuang sebelum diolah menjadi masakan.

Masalah utama yang akan diselesaikan melalui tim Pengabdian kepada Masyarakat ini antara lain perlunya tambahan penghasilan selain dari aktivitas mencari ikan di laut. Melalui PKM Pengabdian kepada masyarakat, diharapkan dapat diadakan Pelatihan Digital Marketing Strategy of Blue Poisson Extraction sebagai upaya pemberdayaan istri nelayan di desa Mayangan Kota Probolinggo dan terbentuknya kaderisasi digital marketing strategy of blue Poisson extraction untuk keberlangsungan program. Persoalan utama antara lain peningkatan hasil untuk Ibu Rumah Tangga atau istri nelayan. Dalam hal segi sosial kehidupan sosial masyarakat Mayangan kurang memiliki jiwa solidaritas terhadap sesama tetangga dengan hal yang dijumpai yakni kurang pedulinya kehadiran dalam kegiatan gotong royong, dan juga kurangnya kehadiran dalam kegiatan rapat kepala keluarga. Persoalan yang paling penting untuk diselesaikan yaitu permasalahn ekonomi masyarakat Mayangan dengan cara melibatkan istri seorang nelayan untuk meningkatkan hasil ekonomi keluarganya.

Dari keadaan tersebut tim pengabdian berusaha memberikan bekal Pelatihan Digital Marketing Strategy of Blue Poisson Extraction kepada istri nelayan yang tidak bekerja namun berpenghasilan rendah, yang mana bekal ini nantinya dapat dijadikan modal wirausaha bagi masyarakat maupun sebagai usaha yang dapat menjadi tonggak berdirinya usaha-usaha baru yang sejenis ataupun bidang lain. 
Digital Marketing Strategy adalah metode pemasaran yang menggunakan internet melalui website atau aplikasi pada smartphone [10]. Strategi ini memungkinkan pengguna mudah untuk mencari produk yang diperlukan, mencari promo atau diskon, membaca deskripsi produk, menghubungi penjual secara online, kemudahan dalam sistem pembayaran, menjaga kualitas dan adanya garansi barang kembali jika tidka sesuai bagi pembeli [11]. E-commerce merupakan salah satu wujud dari Digital Marketing Strategy karena memenuhi unsur-unsur kemudahan bagi pembeli. Saat ini, e-commerce mudah diakses oleh pengguna melalui aplikasi yang tersemat pada smartphone. Contoh e-commerce antara lain Bukalapak, olx, Blibli, Shopee, Lazada, dan Tokopedia [12]. Digital Marketing Strategy juga dapat dilakukan melalui Social Media, Facebook. Instagram, Twitter, maupun Whastapp [12].

Pelatihan Digital Marketing Strategy mempunyai kemiripan dengan program pengabdian yang menghasilkan produk berupa kerudung "Al-Kattar" [13]. Kemiripan terletak pada penggunaan akun social media yaitu Instagram dan juga Facebook. Program pengabdian yang dilakukan sebelumnya, mendapatkan respon positif baik dari masyarakat yang menjadi mitra maupun konsumen. Salah satu rspon positif tersebut yaitu meningkatnya penjualan kerudung hanya dalam waktu satu bulan. Beberapa kendala yangd iahdapi selama pelatihan yaitu kurangnya pelaku produksi yang aktif dan enerjik. Mayoritas pelaku produksi berada pada rentang usia paruh baya sehingga masih kesulitan dalam menggunakan smartphone maupun laptop.

Pelatihan Digital Marketing dengan memanfaatkan social media juga dilakukan dengan sasaran UMKM dengan menggunakan social media Facebook, BBM, Whatsapp, dan Instagram [14]. Pelatihan ini menghasilkan penjualan produk yang meningkat, meningkatnya jumlah konsumen, jaringan promosi yang semakin luas, serta berkurangnya penggunaan dana pemasaran yang sbeelumnya menggunakan pencetakan brosur. Berbeda dengan program pengabdian sebelumnya, kendala yang dihadapi pada pelatihan ini yaitu kurangnya waktu pendampingan pada tahap pemanfaatan sistem pembayaran melalui m-banking. Hal ini mengakibatkan sistem pembayaran terhambat untuk dianalisis.

Manfaat yang ingin dicapai dari kegiatan ini yakni: masyarakat sasaran diharapkan dapat menjadi nilai tambah kepiting tapal kuda di Desa Mayangan Kota Probolinggo. Manfaat yang ingin dicapai dari kegiatan ini yakni masyarakat sasaran diharapkan dapat menjadi nilai tambah kepiting tapal kuda di Desa Mayangan Kota Probolinggo. Bagi Mahasiswa dapat mengimplementasikan teknik Pelatihan Digital Marketing Strategy of Blue Poisson sebagai Upaya Pemberdayaan Istri Nelayan di Desa Mayangan Kota Probolinggo.

\section{METODE}

Pelatihan Digital Marketing Strategy of Blue Poisson Extraction sebagai Pemberdayaan Istri Nelayan di Desa Mayangan Kota Probolinggo merupakan program yang ditujukan kepada masyarakat Desa Mayangan untuk meningkatkan nilai tambah pada kepiting tapal kuda. Permasalahan yang dihadapi adalah bahwa kepiting tapal kuda hanya dimanfaatkan daging dan telurnya saja oleh masyarakat, oleh karena itu tim PKM-M Universitas Muhammadiyah Malang akan memanfaatkan racun biru kepiting tapal kuda.

Pengumpulan data dilaksanakan dengan cara penyebaran angket keterlaksanaan program di setiap pertemuan. Adapun format angket adalah sebagai berikut.

Tabel 1. Angket Keterlaksanaan Program

\begin{tabular}{cccccc}
\hline Pertemuan Ke- & Kegiatan & \multicolumn{3}{c}{ Skor } \\
\cline { 3 - 5 } & & 1 & 2 & 3 & 4 \\
\hline 1. & & & \\
\hline 2. & & & \\
\hline 3. & & & \\
\hline 4. & & & \\
\hline 5. & & & \\
\hline
\end{tabular}



Keterangan :
1 : Tidak Memuaskan
2 : Kurang Memuaskan
3 : Memuaskan
4 : Sangat Memuaskan

Pengolahan data dilakukan dengan cara menganalisis dan mensinkronkan antara tahapantahapan program dengan angket keterlaksanaan program Pelatihan Digital Marketing Strategy Of Blue Poisson Extraction Sebagai Pemberdayaan Istri Nelayan di Desa Mayangan Kota Probolinggo.

Metode pelaksanaan atau tahapan-tahapan program yang dibuat oleh tim PKM-M Universitas Muhammadiyah Malang adalah sebagai berikut.

\begin{tabular}{|l|}
\hline Tahap Administrasi \\
Tahap Pembinaan \\
2. Pembuatan Media/materi program \\
3. Pembentukan kaderisasi \\
\hline
\end{tabular}

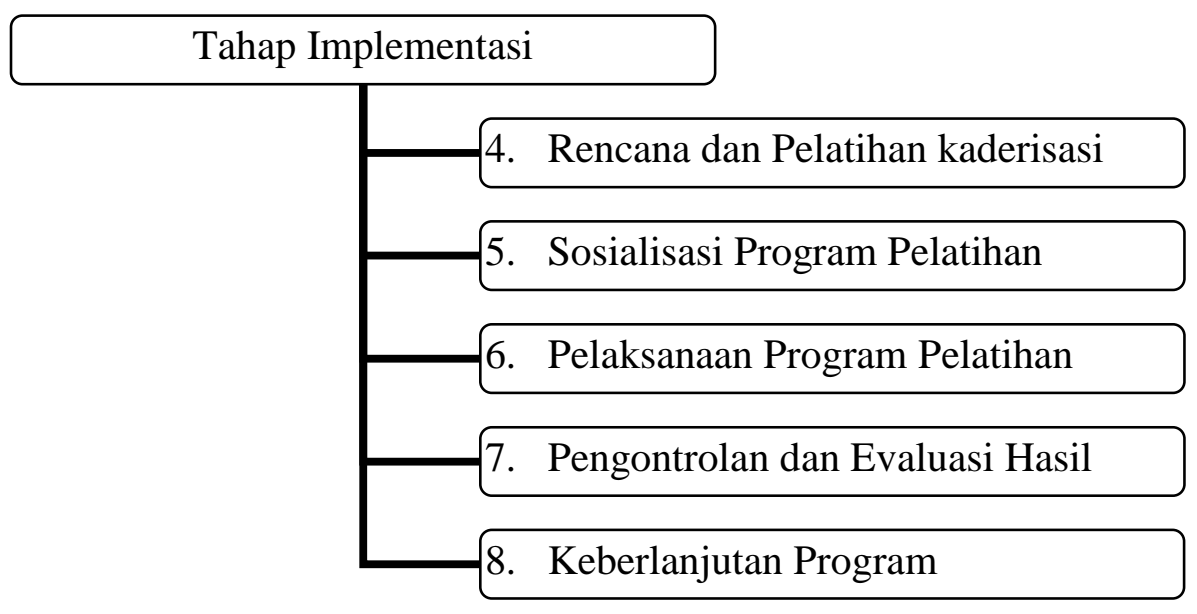

Gambar 1 Metode Pelaksanaan program

\section{1) Tahap Administrasi}

Tahap ini, tim PKM-M Universitas Muhammadiyah Malang melakukan survei pada tempat yang dituju untuk meminta izin kepada pihak yang berwenang untuk melaksanakan Program Pelatihan Digital Marketing Strategy of Blue Poisson Extraction sebagai Pemberdayaan Istri Nelayan di Desa Mayangan Kota Probolinggo terhadap pengurus Desa Mayangan Kota Probolinggo. Survei ini bertujuan untuk mendapatkan data faktual. Tahap selanjutnya yaitu pembuatan media atau materi pada program pelatihan ini, dalam tahap ini tim PKM-M Universitas Muhammadiyah Malang akan membuat media agar informasi mudah untuk dipahami kepada masyarakat sasaran.

Masyarakat sasaran dapat baca tulis, sehingga tim PKM-M Universitas Muhammadiyah Malang membuat media berbasis power point dan video dari aplikasi Adobe Premire. Media 
didesain dengan menarik oleh Tim PKM-M Universitas Muhammadiyah Malang agar materi yang disampaikan dapat diterima dengan baik.

Susunan materi pada Program Pelatihan Digital Marketing Strategy of Blue Poisson Extraction yaitu:

Tabel 2 Susunan Materi Program Pelatihan

\begin{tabular}{|c|c|c|c|c|c|}
\hline No & $\begin{array}{c}\text { Pertemuan } \\
\text { Pelatihan }\end{array}$ & Materi & $\begin{array}{l}\text { Kontribu } \\
\text { Masyarak }\end{array}$ & & Metode \\
\hline 1 & Pelatihan 1 & $\begin{array}{l}\text { Pengenalan anatomi dari kepiting tapal } \\
\text { kuda, dan Kandungan gizi pada kepiting } \\
\text { tapal kuda }\end{array}$ & $\begin{array}{l}\text { Pemateri } \\
\text { memberikan } \\
\text { tanya jawab }\end{array}$ & sesi & $\begin{array}{l}\text { Brain } \\
\text { Storming }\end{array}$ \\
\hline 2 & Pelatihan 2 & $\begin{array}{l}\text { Kandungan gizi racun biru pada kepiting } \\
\text { tapal kuda, dan Manfaat racun biru } \\
\text { kepiting tapal kuda pada kesehatan. }\end{array}$ & $\begin{array}{l}\text { Pemateri } \\
\text { memberikan } \\
\text { tanya jawab }\end{array}$ & sesi & $\begin{array}{l}\text { Brain } \\
\text { Storming }\end{array}$ \\
\hline 3 & Pelatihan 3 & $\begin{array}{l}\text { Alat dan bahan yang digunakan, dan Cara } \\
\text { memperoleh ekstrak racun biru pada } \\
\text { kepiting tapal kuda. }\end{array}$ & $\begin{array}{l}\text { Pemateri } \\
\text { memberikan } \\
\text { tanya jawab }\end{array}$ & sesi & $\begin{array}{l}\text { Simulasi } \\
\text { dan Brain } \\
\text { Storming }\end{array}$ \\
\hline 4 & Pelatihan 4 & $\begin{array}{l}\text { Pengemasan racun biru kepiting tapal } \\
\text { kuda, dan } \\
\text { Promosi racun biru pada kepiting tapal } \\
\text { kuda. }\end{array}$ & $\begin{array}{l}\text { Pemateri } \\
\text { memberikan } \\
\text { tanya jawab }\end{array}$ & sesi & $\begin{array}{l}\text { Simulasi } \\
\text { Brain } \\
\text { Storming }\end{array}$ \\
\hline 5 & Pelatihan 5 & $\begin{array}{l}\text { Target pemasaran racun biru kepiting } \\
\text { tapal kuda. }\end{array}$ & $\begin{array}{l}\text { Pemateri } \\
\text { memberikan } \\
\text { tanya jawab }\end{array}$ & sesi & $\begin{array}{l}\text { Simulasi } \\
\text { Brain } \\
\text { Storming }\end{array}$ \\
\hline
\end{tabular}

2) Tahap Pembinaan

Tahap ini, masyarakat sasaran yaitu masyarakat istri nelayan yang tidak bekerja namun penghasilannya rendah di Desa Mayangan, dimana akan dibentuk kaderisasi pemprograman yang bertujuan untuk memfasilitasi Program Pelatihan Digital Marketing Strategy of Blue Poisson Extraction sebagai Pemberdayaan Istri Nelayan di Desa Mayangan Kota Probolinggo agar berjalan dengan lancar.

Kaderisasi dimusyawarahkan untuk pemilihan ketua, bendahara, sekretaris, dan anggota dimana kaderisasi dipilih dari masyarakat setempat. Tugas ketua adalah mengontrol dan mengatur Program Pelatihan Digital Marketing Strategy of Blue Poisson Extraction. Tugas bendahara adalah mengatur pemasukkan dan pengeluaran dalam Program Pelatihan Digital Marketing Strategy of Blue Poisson Extraction. Tugas sekretaris adalah melaporkan banyaknya masyarakat yang mengikuti Program Pelatihan Digital Marketing Strategy of Blue Poisson Extraction sebagai Upaya Pemberdayaan Istri Nelayan di Desa Mayangan Kota Probolinggo.

3) Tahap Implementasi

Tahap ini terdiri dari rencana dan pelatihan kaderisasi, sosialisasi program pelatihan, pelaksanaan program pelatihan, pengontrolan dan evaluasi hasil, dan keberlajutan program.

a. Rencana dan Pelatihan Kaderisasi

Rencana dalam program pelatihan kaderisasi ini membutuhkan waktu 1 bulan dimana diadakan pertemuan 5 kali.

b. Sosialisasi Program Pelatihan 
Tahap ini tim PKM-M Universitas Muhammadiyah Malang melaksanakan Program Pelatihan Digital Marketing Strategy of Blue Poisson Extraction sebagai Upaya Pemberdayaan Istri Nelayan di Desa Mayangan Kota Probolinggo dengan menjelaskan bagian penghasil racun biru pada kepiting tapal kuda serta menjelaskan bagaimana racun biru dapat keluar dari kepiting tapal kuda. Pada sosialisasi ini tim PKM-M Universitas Muhammadiyah Malang menyewa tempat untuk program pelatihan, LCD serta proyektor sebagai salah satu pelengkap penunjang penjelasan kepada masyarakat sasaran.

c. Pelaksanaan Program Pelatihan

Tahap ini adalah tahap praktik dari Program Pelatihan Digital Marketing Strategy of Blue Poisson Extraction sebagai Upaya Pemberdayaan Istri Nelayan di Desa Mayangan Kota Probolinggo. Program pelatihan yang diberikan berawal dari pemberian materi tentang kepiting tapal kuda dan racun biru yang terdapat pada kepiting tapal kuda.

Tahap selanjutnya dari Program Pelatihan Digital Marketing Strategy of Blue Poisson Extraction adalah partisipasi aktif dari masyarakat sasaran dalam mengekstrak, mengemas, dan mempromosikan racun biru kepiting tapal kuda ke masyarakat luar.

Masuk pada tahap selanjutnya yaitu promosi racun biru kepiting tapal kuda, dimana akan dijelaskan bagaimana cara mempromosikan racun biru kepiting tapal kuda pada masyarakat luar dan instalasi dibidang tertentu. Promosi yang akan digunakan salah satunya adalah promosi di Digital Marketing Strategy. Media cetak juga digunakan dalam proses promosi racun biru kepiting tapal kuda seperti Koran, majalah, brosur, banner dan media cetak lainnya.

d. Pengontrolan dan Evaluasi Hasil

Tahap ini merupakan tahap pengontrolan, dimana dilihat dari masyarakat sasaran dapat menerapkan secara langsung Program Pelatihan Digital Marketing Strategy of Blue Poisson Extraction dengan tanpa bantuan.

e. Keberlanjutan Program

Tahap ini merupakan tahap akhir dari Program Pelatihan Digital Marketing Strategy of Blue Poisson Extraction sebagai Upaya Pemberdayaan Istri Nelayan di Desa Mayangan Kota Probolinggo dimana setelah program pelatihan ini selesai diharapkan agar kegiatan pemanfaatan racun biru kepiting tapal kuda ini berlanjut seterusnya di Desa Mayangan bahkan sampai ke desa sekitarnya.

Jadwal pelatihan dapat dilihat pada tabel 1

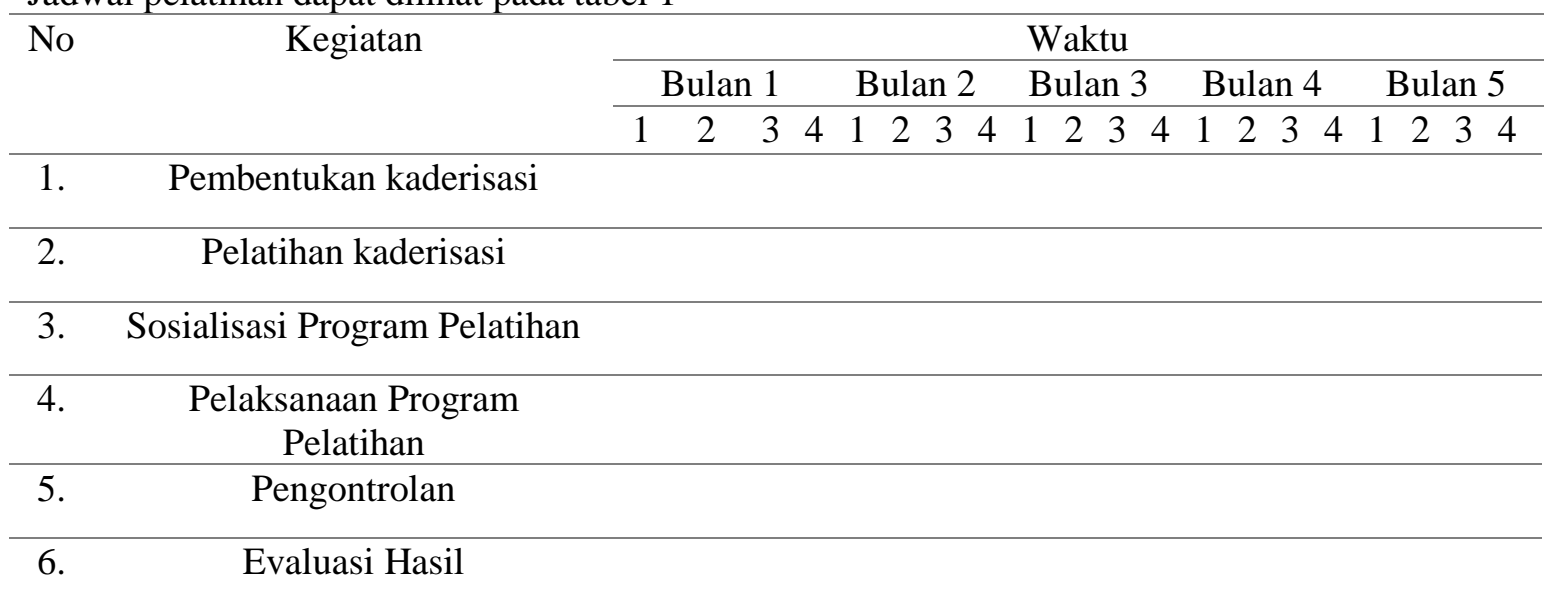




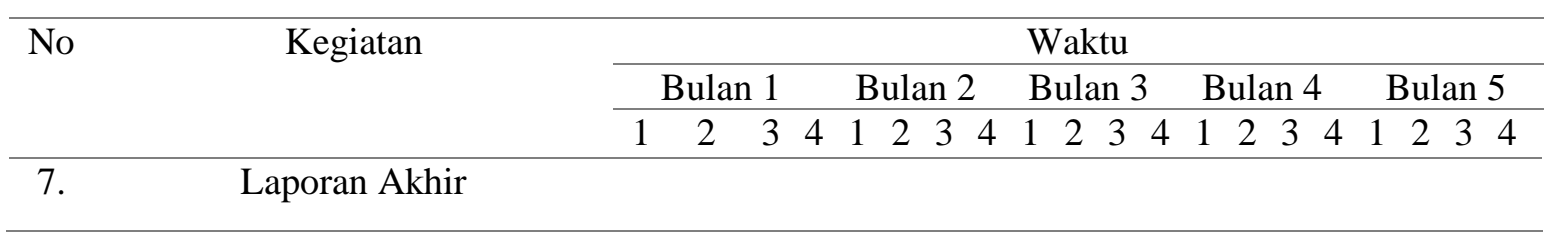

\section{HASIL DAN PEMBAHASAN}

Tahap pembentukan kaderisasi dilaksanakan pada Tanggal 11 Mei 2019. Kaderisasi dimaksudkan untuk menjaga stabilitas atau keberlangsungan produksi ekstraksi racun biru kepiting tapal kuda. Pemberian tanggung jawab kepada setiap peserta pelatihan dapat menjadikan mitra, dalam hal ini istri nelayan, fokus terhadap kegiatan yang harus dikerjakan. Mitra terdiri dari 6 orang dengan pembagian tugas sebagai ketua, analis keuangan, penanggung jawab bidang produksi, penanggung jawab bidang pemasaran, dan penanggung jawab bidang penjualan produk. Masing-masing tugas tersebut dibebankan dengan hasil yang ditargetkan. Secara keseluruhan, setiap miyra berkoordinasi dan bermusyawarah untuk saling membantu jika terdapat permasalahan di masing-masing tugas.

Pelatihan kaderisasi difokuskan pada setiap jobdesk. Diawali dari analis pembukuan, mitra diberikan contoh pembukuan dengan menggunakan manual book maupun komputer. Meskipun mitra tidak mempunyai komputer, mitra tetap dilatih untuk mengisi form pembukuan keuangan melalui Excel. Pelatihan terdiri dari beberapa materi antara lain: penjualan, pembelian, pendapatan, pengeluaran, laba dan rugi, serta pengelolaan distribusi jasa pengiriman. Setiap materi diberikan contoh riil agar dapat dipahami. Setiap materi juga disertakan komponen-komponen yang dapat dimasukkan pada setiap materi. Misalnya, pada materi pendapatan, terdapat beberapa komponen antara lain: sumbangan modal dari pihak sponsor, pendapatan kotor, pendapatan bersih, pendapatan tetap, dan modal tetap. Pelatihan ini berlangsung dalam waktu 3 jam dengan antusiasme mitra terlihat ketika tanya jawab. Mitra sangat tertarik dengan aplikasi smartphone tentang pembukuan sederhana dan penghitungan laba atau rugi usaha. Kendala yang dihadapi saat pelatihan ini yaitu adanya peserta yang tidak mempunyai smartphone. Mitra ini selanjutnya ditugaskan pada produksi ekstraksi racun biru kepiting tapal kuda. Kendala lain yaitu adanya mitra yang tidak dapat mengendarai motor sehingga tidak memungkinkan untuk ditugaskan pada bidang pemasaran. Oleh sebab itu, mitra selanjutnya ditugaskan pada bagian pembukuan keuangan. Secara keseluruhan, tahapan pelatihan ini mempunyai kendala yang dapat teratasi dengan kemmapuan yang dimiliki ibu-ibu lainnya.

Tahapan pelatihan selanjutnya yaitu optimalitas ekstraksi dan pengemasan racun biru. Racun biru biasa dikeluarkan oleh mitra untuk dibuang dengan cara mencongkel bagian ekor kepiting yang menyebabkan kematian kepiting secara langsung. Kepiting tapal kuda yang hanya dimanfaatkan darah birunya sebenarnya dapat diekstraksi tanpa membunuh atau menyakiti kepiting. Hal ini kemudian dilatihkan kepada mitra dengan cara menggunakan jarum injeksi yang berukuran kecil. Jarum ini ditusukkan pada bagian ekor kepiting kemudian menarik ujung injeksi agar racun biru masuk ke dalam pipa injeksi. Selanjutnya, mitra dilatih untuk membuat botol kaca sebagai wadah racun biru agar steril dan tertutup rapat. Penyimpanan racun biru harus benar-benar diperhatikan. Hal ini mengingat pengiriman racun biru kepada pembeli membutuhkan waktu beberapa hari. Agar kualitas racun biru terjaga dengan baik, racu biru dibekukan sampai pada suhu minus 5 derajat Celcius. Pengemasan dilakukan dengan menambahkan bubble wrap dan sterofoam agar menjaga kualitas keenceran darah biru dan mencegah pecahnya botol kaca. Berdasar tahapan pelatihan ini, ekstraksi racun biru pada 25 kepiting menghasilkan $100 \mathrm{ml}$ darah biru.

Tahapan selanjutnya yaitu pelatihan pembuatan akun e-commerce. Pelatihan ini dilaksanakan pada Tanggal 14 Mei 2019. Akun dibuat pada e-commerce Shopee terlebih dahulu. Mitra dibantu menginstall aplikasi Shopee pada smartphone masing-masing. Setelah terinstal, mitra melengkapi profil akun berupa foto, deksripsi produk, dan nomor rekening. Foto produk yang diupload yaitu botol berukuran $5 \mathrm{ml}$ dengan deskripsi produk berupa fungsi dan manfaat dari racun biru. Penetapan harga jual produk ditentukan dengan analisis keuntungan nilai jual produk. Setelah deskripsi produk lengkap terisi, mitra dibantu untuk uji coba chat antara penjual dan pembeli. Chat ini digunakan sebagai sarana komunikasi dengan pembeli. Mitra diberi template 
balasan chat otomatis tentang sapaan dan deskripsi waktu pelayanan. Fitur lain yang juga diujicoba yaitu proses checkout atau apabila ada pembeli yang telah memasukkan ke dalam keranjang kemudian mentransfer. Mitra dibantu mengelola pesanan dan mengecek pembayaran melalui mbanking. Kendala yang dihadapi mitra yaitu kurang tangkas dalam mengoperasikan fitur-fitur pada e-commerce. Hal ini membuat wkatu pelatihan cukup lama karena terdapat beberapa proses pengelolaan fitur yang diulang-ulang. Kendala ini dapat teratasi apabila terdapat mitra yang paham terlebih dahulu dan bersedia memantu mitra lain menjadi paham. Adapun kegiatan pelatihan pengelolaan e-commerce dapat dilihat pada Gambar 2.

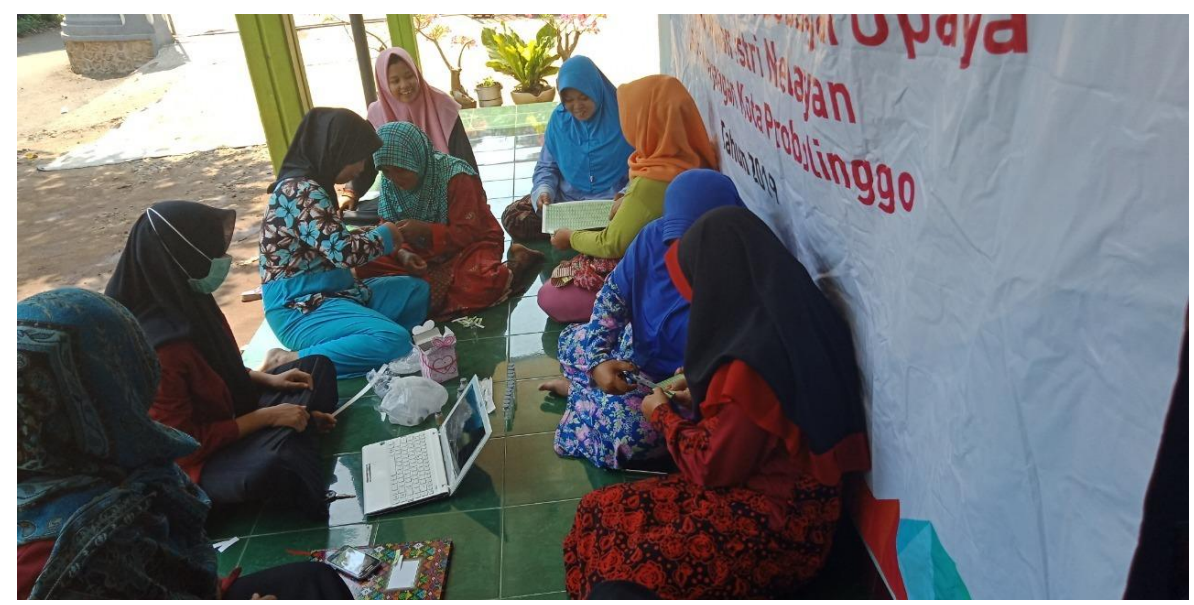

Gambar 2 Pelatihan Pengelolaan E-Commerce

Tahapan selanjutnya yaitu uji coba pemasaran dan penjualan produk. Produk yang telah dikemas sebelumnya disiapkan untuk dikemas. Pemasaran dilakukan secara online menggunakan bantuan social media sebagai sarana promosi. Selanjutnya, penanggung jawab bidang pemasaran diajak ke kantor ekspedisi yang menjadi mitra e-commerce terdekat. Di kantor tersebut, mitra diajak untuk melakukan simulasi pengiriman barang. Simulasi diawali dari pengisian data penjual dan pembeli. Setelah itu, mitra dibantu untuk melakukan pelacakan pengiriman barang melalui smartphone.

Tahap evaluasi dilakukan minggu pertama setelah program pelatihan. Tahap evaluasi dilakukan terhadap tiga hal yaitu, evaluasi produk, evaluasi strategi pemasaran, dan evaluasi penggunaan e-commerce maupun sosial media. Evaluasi produk dilakukan dengan cara mengecek bersama-sama kualitas produk untuk minggu pertama. Produk yang disimpan pada kulkas dengan suhu minus 5 derajat Celcius tidak ada perubahan dari segi warna maupun kekentalannya. Hal ini berarti daya simpan produk dalam waktu satu minggu masih cukup bagus. Kemudian mengecek produk dalam kemasan pengiriman apakah masih berkualitas baik atau tidak. Saat pengecekan berlangsung, kondisi racun biru dalam kemasan pengiriman sudah mencair seluruhnya namun tidka ada perubahan warna maupun kekentalannya. Hal ini berarti, kualitas produk secara keseluruhan dalam rentang waktu 1 minggu masih baik.

Evaluasi strategi pemasaran dilakukan dengan cara mengecek setiap akun e-commerce terkait berapa pembeli yang telah memasukkan ke dalam keranjang, berapa jumlah pembeli yang berkomunikasi dengan penjual, dan berapa banyak yang memfollow akun racun biru. Dalam waktu 1 minggu, masih belum ada respon dari pembeli. Hal ini dimungkinkan masih kurangnya informasi terhadap pentingnya racun biru pada bidang medis. Tim mengambil tindak lanjut berupa pembuatan akun pada e-commerce internasional yaitu alibaba. Jika pada akun lain disebutkan penjualan dilakukan dalam satuan liter, maka tim membuat promo untuk pembelian 500 ml dengan sistem preorder 14 hari. Hal ini untuk mengantisipasi apabila kepiting tapal kuda sulit untuk ditangkap.

Evaluasi pengelolaan e-commerce yang dilakukan yaitu dengan cara memberikan angket kepada mitra. Angket berisi indikator keterlaksanaan program beserta respon dari mitra. Berdasar hasil angket yang telah dianalisis, mitra merasa sangat puas terhadap pelatihan yang diberikan dengan tema pengelolaan e-commerce. Mitra memberikan alasan bahwa setelah dilakukan promosi 
melalui aplikasi e-commerce, setiap hari mitra mengecek akun tersebut untuk mengecek keberadaan pembeli. Mitra mengaku tidak sabar untuk merespon dan menindaklanjuti pembelian racun biru melalui ekspedisi. Respon yang paling buruk pada angket yaitu materi pembukuan keuangan yang mendapatkan hasil cukup memuaskan. Alasan dari mitra yaitu lemahnya kemampuan berhitung dan menganalisis keuangan secara sederhana, terutama menentukan komponen mana yang termasuk pengeluaran tetap dan pengeluaran tambahan. Untuk mengantisipasi hal tersebut, tim menjelaskan kembali tentang pembukuan keuangan pada evaluasi akhir.

\section{KESIMPULAN}

Keseluruhan pelatihan Digital Marketing Strategy pada istri nelayan di Desa Mayangan mempunyai hasil sebagai berikut:

1. Ekstraksi racun biru pada kepiting tapal kuda dilakukan dengan sangat baik dan tidak bersifat membunuh kepiting tersebut. Mitra sudah terampil dalam ekstraksi racun biru menggunakan jarum suntik dan langsung melepaskan kepiting ke perairan.

2. Mitra cukup terampil dalam mengelola pembukuan dengan bantuan Excel walaupun belum terampil dalam berhitung. Perbedaan komponen pada setiap indikator pembukuan belum dapat dibedakan oleh mitra.

3. Penggunaan e-commerce sangat bermanfaat bagi mitra. Mitra merasa antusias mengikuti setiap tahapan pengelolaan e-commerce dan memberikan kontribusi ide-ide untuk promo atau diskon pada e-commerce.

\section{SARAN}

Penelitian lebih lanjut dapat dilakukan dengan cara mengkaji prosedur pengolahan darah biru kepiting tapal kuda di bidang biomedis dan biokimia. Penelitian yang selanjutnya juga dapat ditambahkan pengujian kandungan darah biru kepiting tapal kuda di Desa Mayangan. Program pengabdian kepada masyarakat dapat dilanjutkan untuk melatih masyarakat di Desa Mayangan lainnya untuk memanfaatan darah biru dalam bentuk produk olahan baik berupa bahan baku vaksin siap pakai maupun di bidang biomedik.

\section{UCAPAN TERIMA KASIH}

Penulis mengucapkan terima kasih kepada Direktorat Jenderal Pembelajaran dan Kemahasiswaan Kementerian Riset, Teknologi dan Pendidikan Tinggi yang telah memberi dukungan financial terhadap penelitian ini.

\section{DAFTAR PUSTAKA}

[1] P. Rini, "Peran nelayan perempuan dalam meningkatkan pendapatan masyarakat pesisir di desa tompotana kabupaten takalar sulawesi selatan," Info Tek. EBON, vol. 15, no. 2, pp. 79 90, 2018.

[2] W. Handoko, S. Marwah, and R. Ardhanariswari, "Pembentukan Model Pemberdayaan Perempuan Nelayan di Daerah Tertinggal The Establishment of Empowerment Model of Fish Monger Woman in Underdeveloped Village," no. 107.

[3] S. Suharto, "Karakteristik Darah Mimi ( Limulus sp ) sebagai Pendeteksi Bakteri Kontaminan Penghasil Endotoksin pada Produk Perikanan," vol. 7, no. 1, pp. 9-14, 2018.

[4] L. Meilana, Y. Wardiatno, N. A Butet, and M. Krisanti, MORPHOLOGICAL CHARACTER AND MOLECULAR IDENTIFICATION WITH COI GENE MARKER OF HORSESHOE CRABS (Tachypleus gigas) AT COASTAL WATERS OF NORTHERN JAVA ISLAND, vol. 8. 2016.

[5] Y. van Bergen, BLUE BLOODS: HOW A CRAB MAKES ITS SHELL, vol. 208. 2005.

[6] S. Nanda and P. K. Das, "Medicinal Efficacy of Rose Plant: A Mini Review," vol. 3, no. 
10, pp. 23-26, 2015.

[7] P. Gisler and M. Michael, "Companions at a Distance : Technoscience, Blood, and the Horseshoe Crab," vol. 19, pp. 115-136, 2011.

[8] K. B. Ma, T. P. Ma, J. A. Ms, M. L. S. A. Cm, and B. W. Ms, "Illustrations for Health Assessment Techniques of the Atlantic Horseshoe Crab , Limulus polyphemus," p. 2, 2012.

[9] T. Maloney, R. Phelan, and N. Simmons, "Saving the horseshoe crab: A synthetic alternative to horseshoe crab blood for endotoxin detection," PLOS Biol., vol. 16, no. 10, p. e2006607, Oct. 2018.

[10] R. Rizki, A. Putra, W. S. Wardhono, and M. A. Akbar, "Pengembangan Permainan Trading Card Augmented Reality Bertema Perang Baratayuda," vol. 2, no. 10, 2018.

[11] A. Wardhana, "STRATEGI DIGITAL MARKETING DAN IMPLIKASINYA PADA KEUNGGULAN," no. August, 2018.

[12] T. Pradiani, V. Penjualan, and S. Malang, "TERHADAP PENINGKATAN VOLUME PENJUALAN HASIL," vol. 11, pp. 46-53, 2017.

[13] K. A.- Kattar et al., "Pelatihan Teknik Social Media Marketing sebagai Sarana Pemasaran Produk Pelatihan Teknik Social Media Marketing sebagai Sarana Pemasaran Produk pada Konveksi Kerudung ‘ Al- Kattar’ Di Kelurahan Merjosari , Malang,” no. October, 2018.

[14] M. Novita, "Sarana dan Prasarana Yang Baik Menjadi Bagian Ujung Tombak Keberhasilan Lembaga Pendidikan Islam," NUR EL-ISLAM J. Pendidik. dan Sos. Keagamaan, vol. 4, no. 2, pp. 97-129, 2017. 